\title{
Investigation of the Optical and Electrical Properties of Composites of PVA-PVP-PEG/ZnO Nanoparticles
}

\author{
${ }^{1}$ Ahlaam J. Zaier, ${ }^{1}$ Entisar E. Al-Abodi and ${ }^{2}$ Bushra H. Hussein \\ ${ }^{1}$ Department of Chemistry, College of Education for Pure Science Ibn Al-Haitham, \\ ${ }^{2}$ Department of Physics, College of Education for Pure Science Ibn Al-Haitham, \\ University of Baghdad, Baghdad, Iraq \\ tagreedmm2000@gmail.com
}

\begin{abstract}
In the current study, we investigated the dielectric and optical properties of composite consist of a mixture of (PVA, PVP and $\mathrm{PEG}$ ) with various quantities of $(\mathrm{ZnO})$ nanoparticles. Optical measurement shows that polymeric blend nanocomposites based on PVA-PVP-PEG films have high absorption with different fractions of zinc oxide nanoparticles. The optical energy gaps were allowed direct transition type which decreases with film fractions increasing, i.e., it decreases from 2.9-1.5 eV with different fractions $(0-4)$ of the zinc oxide. The dielectric behavior of composites consists of a mixture of (PVA, PVP and PEG) with various quantities of ( $\mathrm{ZnO}$ ) nanoparticles films has been scrutinized. It appears from the results that the dopant composition has large efficacy on the values of dielectric properties.
\end{abstract}

Key words: $\mathrm{ZnO}-\mathrm{NPs}$, optical properties, dielectric properties, polymeric blend, scrutinized, dielectric

\section{INTRODUCTION}

The mixtures of two or more polymers with/without any chemical bonding between them called polymer blends. The aim of blending more polymers is generating products that are commercially applicable either through unique characteristics or at a lower cost than others may be available (Walsh and Rostami, 1985).

In general, the polymer blends show properties which are better than compared to the properties of the component polymer individually (Rand, 1979). In recent years the nano composites of the polymers have received a lot of attention because of its unique properties (Momen and Farzaneh, 2011). $\mathrm{ZnO}$ is an unfamiliar material with various applications because it is suitable for thermal, electrical, optical (Erdem et al., 2000; Khan and Alam, 2003) and mechanical properties (Liang et al., 2012). ZnO nanoparticles having or fulfilling several functions, therefore, in recent years has increased attention due to it is many considerable properties like solar cells (Sekine et al., 2009; Greene et al., 2005; Hau et al., 2008), intense ultraviolet and infrared absorption, high catalysis activity, chemical stability (Kawaguchi, 2000; Xing et al., 2004; Tang et al., 2006). Particularly because of the powerful interface interaction between the $\mathrm{ZnO}$ nanoparticles and the organic polymer, the polymeric matrix can reinforce the optical and dielectric properties of the polymers (Lee et al., 2008). In this research, we determined electrical and optical characteristics of composites consist of a mixture of (PVA, PVP and PEG) with various quantities of Zinc Oxide $(\mathrm{ZnO})$ nanoparticles

\section{MATERIALS AND METHODS}

All chemicals which used in this study from Merck, Zinc Oxide $(\mathrm{ZnO})$ nanoparticles have synthesized, according to the study (Nejati et al., 2011). A polymeric mixture nanocomposites which contain three polymers: Polyethylene Glycol (PEG, 1000), Poly Vinyl Pyrrolidone (PVP, 40000) and Polyvinyl Alcohol (PVA, 72000) with various quantities of $(\mathrm{ZnO})$ nanoparticles $(0-4 \%)$ have synthesized, according to the study Al-Saadi et al. (2006).

\section{RESULTS AND DISCUSSION}

The optical properties: The spectrum of absorbance, transmittance and reflection for polymeric blend nano composites based on PVA-PVP-PEG films were evaluated as a function of wavelength at different fractions (0-4) of the zinc oxide in Fig. 1-3. The wavelength range of absorbance spectra was $400-1100 \mathrm{~nm}$. From the Fig. 1, the absorbance generally, decreased with increase in wavelength and has relatively low values in the infrared region of the spectrum (Ezenwa, 2012) and an increase in

Corresponding Author: Ahlaam J. Zaier, Department of Chemistry, College of Education for Pure Science Ibn Al-Haitham, University of Baghdad, Baghdad, Iraq, tagreedmm2000@gmail.com 


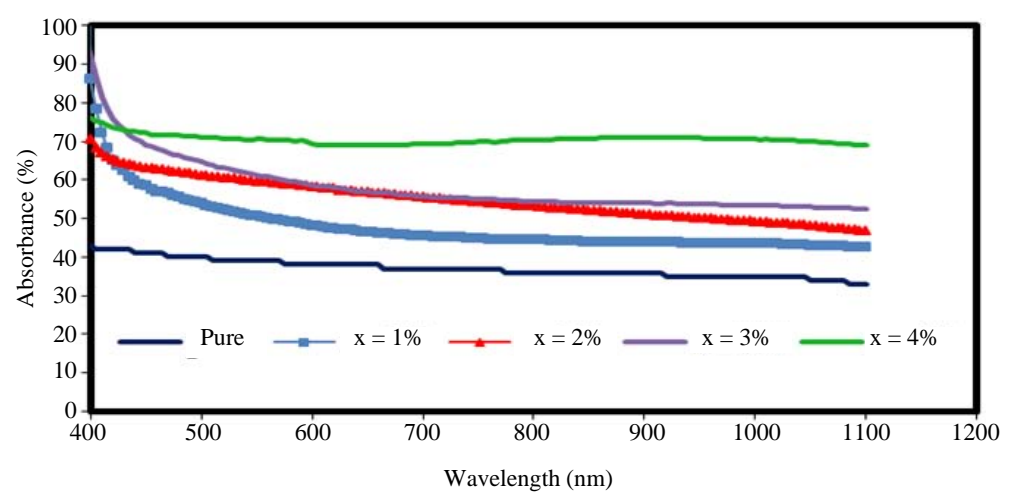

Fig. 1: The absorbance spectrum composite films with different fractions of $\mathrm{ZnO}$

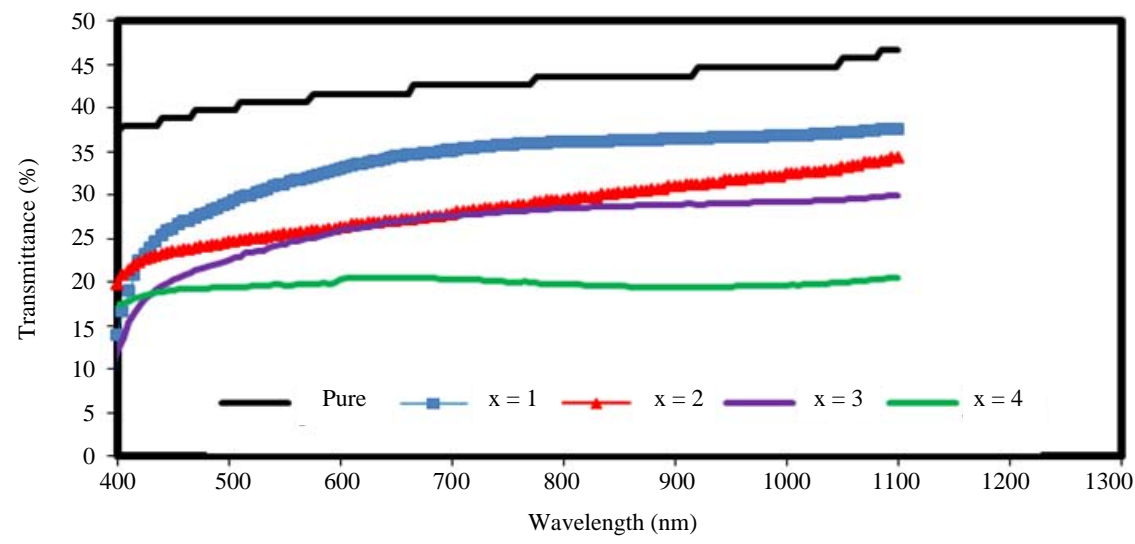

Fig. 2: The transmittance spectrum composite films with different fractions of $\mathrm{ZnO}$

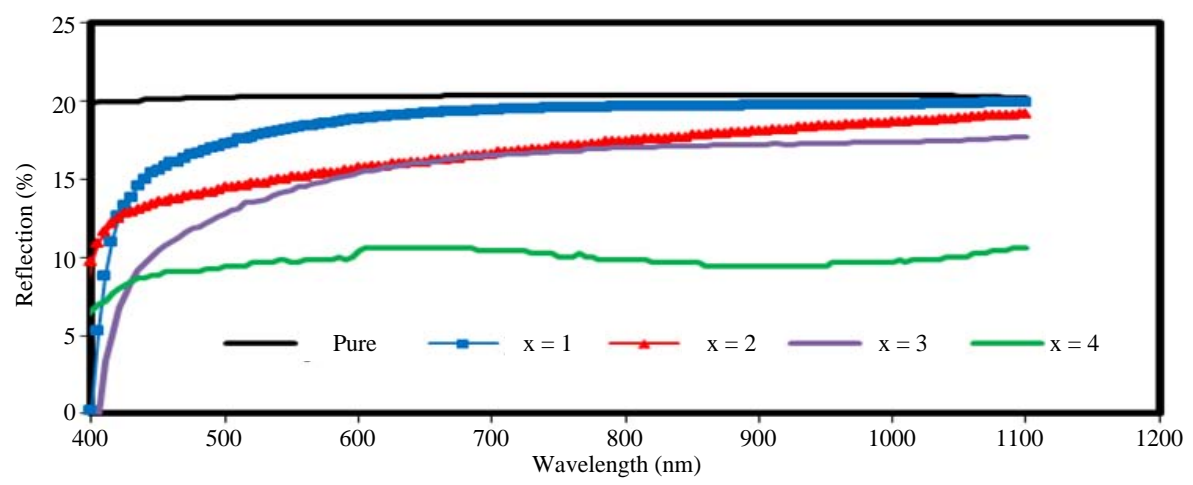

Fig. 3: Reflectance spectra of composite films with different fractions of $\mathrm{ZnO}$

the visible wavelength range as a function of fractions $(0-4)$ of the zinc oxide. A strong absorption of about $90 \%$ was observed at a wavelength of $400 \mathrm{~nm}$ and $(\mathrm{x}=4)$, hence, the film has potential application in the fabrication of solar cell. The conductance of the transmission and reflection spectra displayed in Fig. 2 and 3 is opposite to the absorption spectra.
The values of absorption coefficient which has been calculated using the Urbach Law (Sze, 1981) as in Fig. 4. This shows a high amount of a reached above $\left(10^{5} \mathrm{~cm}^{-1}\right)$. In general, the values of a increaseas a function of fractions $0-4$ of the zinc oxide, this result may be due increase in absorbance and the decreasing of the optical band gap as shown in Table 1. 


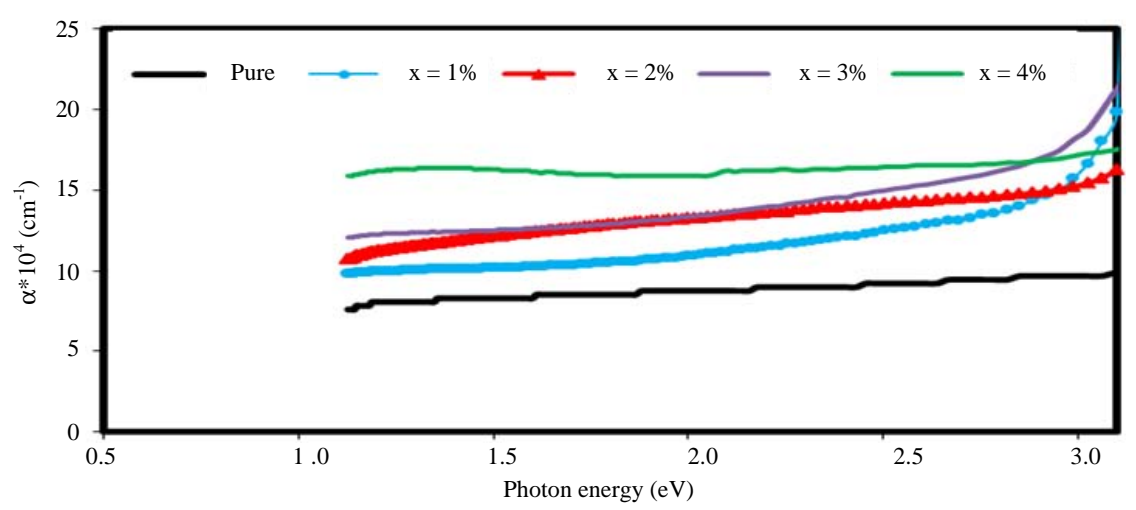

Fig. 4: Variation of absorption coefficient with photon energy of composite films with different fractions of $\mathrm{ZnO}$

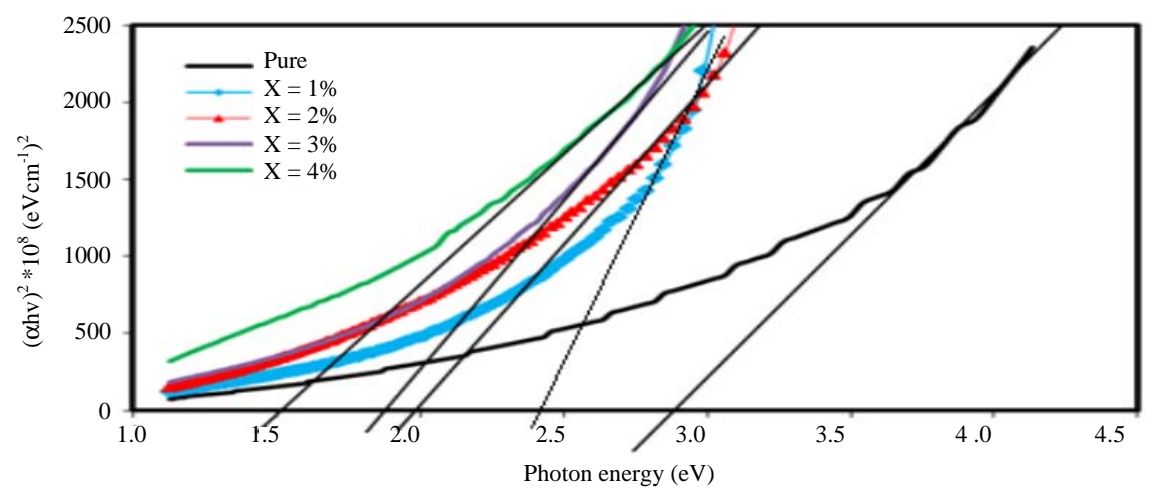

Fig. 5: The $\alpha h v^{2}$ versus photon energy of composite films with different fractions of $\mathrm{ZnO}$

Table 1: Optical constant of composite films with different fractions of $\mathrm{ZnO}$ Optical constant at $\lambda=495 \mathrm{~nm}$

\begin{tabular}{lllllll}
\hline Fraction $(\%)$ & $\mathrm{E}_{\mathrm{p}} \mathrm{opt}(\mathrm{eV})$ & $\alpha \times 10^{4}(\mathrm{~cm})^{-1}$ & $\mathrm{n}$ & $\mathrm{k}$ & $\varepsilon_{\mathrm{\gamma}}$ & $\varepsilon_{\mathrm{i}}$ \\
\hline 0 & 2.9 & 9.212 & 1.8 & 0.36 & 3.16 & 1.3 \\
1 & 2.4 & 12.48 & 1.7 & 0.49 & 2.6 & 1.78 \\
2 & 2 & 14.12 & 1.6 & 0.55 & 2.27 & 1.79 \\
3 & 1.8 & 15 & 1.5 & 0.58 & 2.05 & 1.89 \\
4 & 1.5 & 17 & 1.43 & 0.64 & 1.64 & 1.86 \\
\hline
\end{tabular}

It is clear from Table 1 that the value of a increases from $9.2-17 \times 10^{4} \mathrm{~cm}^{-1}$ with the increase of fractions $0-4$ of the zinc oxide. The value of $\mathrm{E}_{\mathrm{g}}{ }^{\text {pt }}$ computed by using Tauc formula (Ray et al., 2011), the $\mathrm{E}_{\mathrm{g}}^{\mathrm{opt}}$ decreases from 2.9-1.5 eV. As shown in Table 1 and Fig. 5. The increase of fractions $0-4$ of the zinc oxide resulting increasein defect states approaches to the bands resulting decrease in $\left(\mathrm{E}_{\mathrm{g}}^{\mathrm{opt}}\right)$ values.

The relation between $\alpha h v^{2}$ and photon energy $\mathrm{E}(\mathrm{h} v)$ to determine the band gap energy for direct transitions of the sample absorption curves. Variation of optical constants with photon energy for polymeric blend nanocomposites based on PVA-PVP-PEG films with different fractions of zinc oxide nanoparticles is shown in Fig. 6-9 such that the refractive index (n) (Buba and Adelabu, 2010) the extinction coefficient (k) (Khudayer et al., 2018) the realand the imaginary part of the dielectric constant (Kasap, 2002). Table 1 indicates that $n$ valuable decreases with the rise of fractions $0-4$ of the zinc oxide. This behavior is may be because of the decreasing in the reflection as in Fig. 3, this low reflectance value makes polymeric blend nano composites based on PVA-PVP-PEG films with different fractions of zinc oxide nanoparticles an important material for anti-reflection coating. Extinction coefficient $(\mathrm{k})$ in general increment with fractions $0-4$ of the zinc oxide because the increasing in absorption coefficient and absorbance as in Fig. 7. The variables of $\varepsilon_{\mathrm{r}}$ and $\varepsilon_{\mathrm{i}}$ versus photon energy at different fractions $0-4$ of the zinc oxide are shown in Fig. 8 and 9. The $\varepsilon_{\mathrm{r}}$ and $\varepsilon_{\mathrm{i}}$ generally relates to dispersion and loss factor, respectively. Figure 8 it is 1.5 when $x=4$ then decreases with the increase of $\mathrm{E}(\mathrm{h} v)$ similar beaver with refractive index. The $\varepsilon_{\mathrm{r}}$ decrease with increase for fractions $0-4$ of the zinc oxide. Figure 9 , it is seen that, the $\varepsilon_{i}$ decrease with the increase of $\mathrm{E}(\mathrm{hv})$ and fractions $0-4$ of the zinc oxide like absorption coefficient.

Dielectrical properties: The films which prepared were cut into $(20 \times 15 \mathrm{~mm})$ pieces to proper a silver electrode for characterization by specified the dielectric properties a 


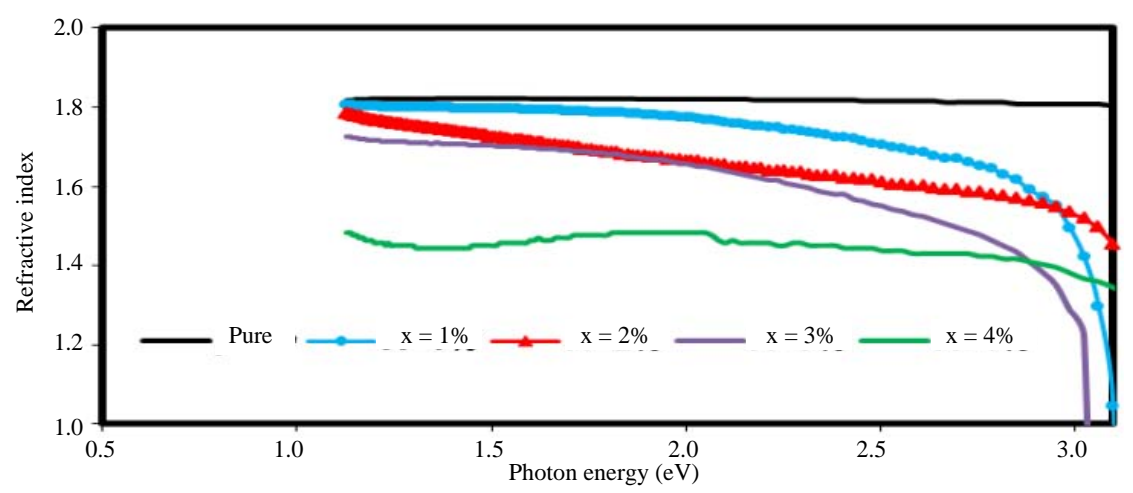

Fig. 6: The refractive index with photon energy of composite films with different fractions of $\mathrm{ZnO}$



Fig. 7: The extinction coefficient with photon energy of composite films with different fractions of $\mathrm{ZnO}$

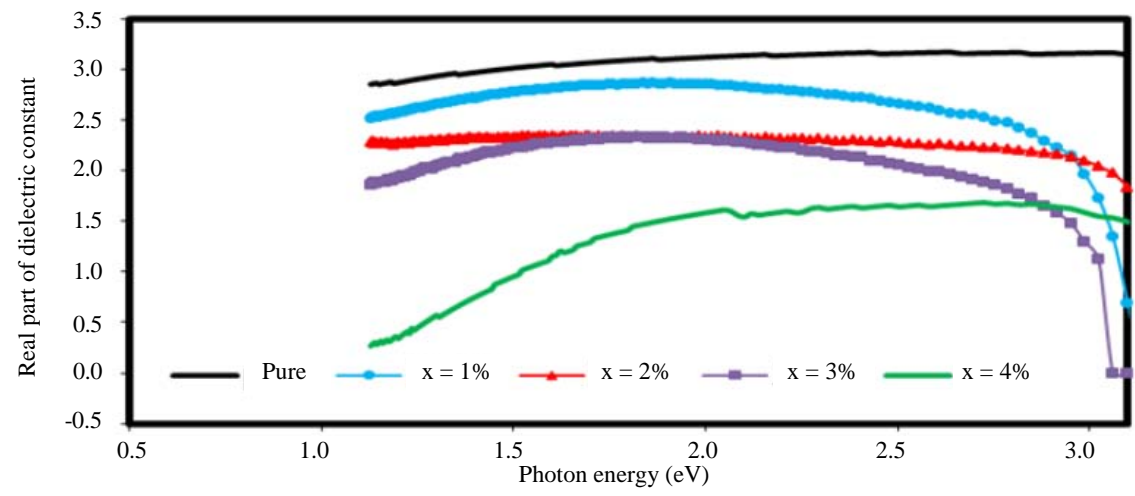

Fig. 8: The real part of dielectric constant with photon energy of composite films with different fractions of $\mathrm{ZnO}$

frequency was used at a range of $50-10^{6} \mathrm{~Hz}$. The dielectric constant $\left(\varepsilon^{\prime}\right)$ (real part) is determined by using the following expression:

$$
\varepsilon^{\prime}=\frac{\mathrm{Cd}}{\varepsilon^{\prime} \mathrm{A}}
$$

where, $\mathrm{C}, \mathrm{d}, \mathrm{A}, \varepsilon^{\circ}$ are measured capacitance, the thickness between the two electrodes and the permittivity of the free, space, respectively. The dielectric loss $\varepsilon^{\prime}(\omega)$ (imaginary part) is described with Eq. 2 (Madakbas et al., 2010) where is tangent delta $(\boldsymbol{\theta})$ :

$$
\varepsilon^{\prime \prime}(\omega)=\varepsilon^{\prime}(\omega) \cdot \tan \theta(\omega)
$$

Electrical conductivity $\sigma$ of above films are measured by the (Eq. 3:)

$$
\sigma=\varepsilon^{\prime} \times \varepsilon^{\circ}
$$




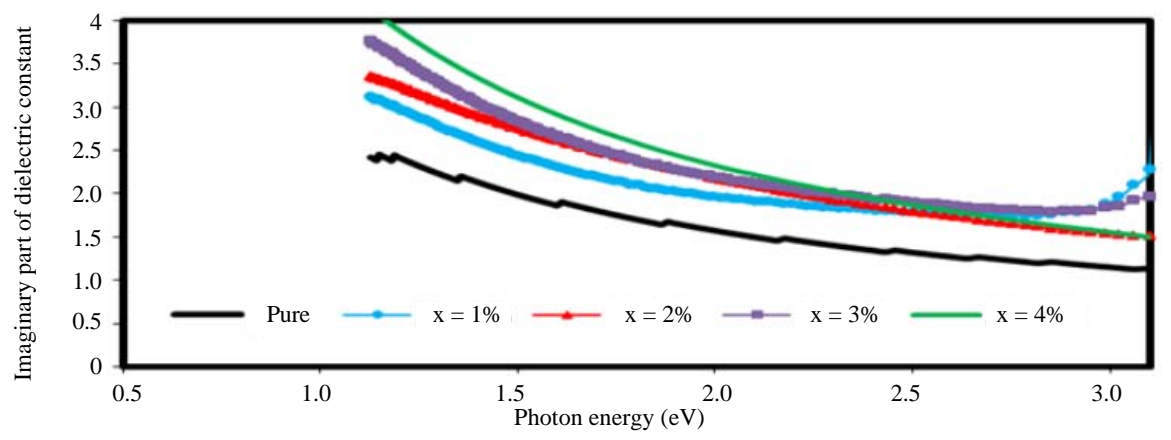

Fig. 9: The imaginary part of dielectric constant versus photon energy of composite films with different fractions of $\mathrm{ZnO}$

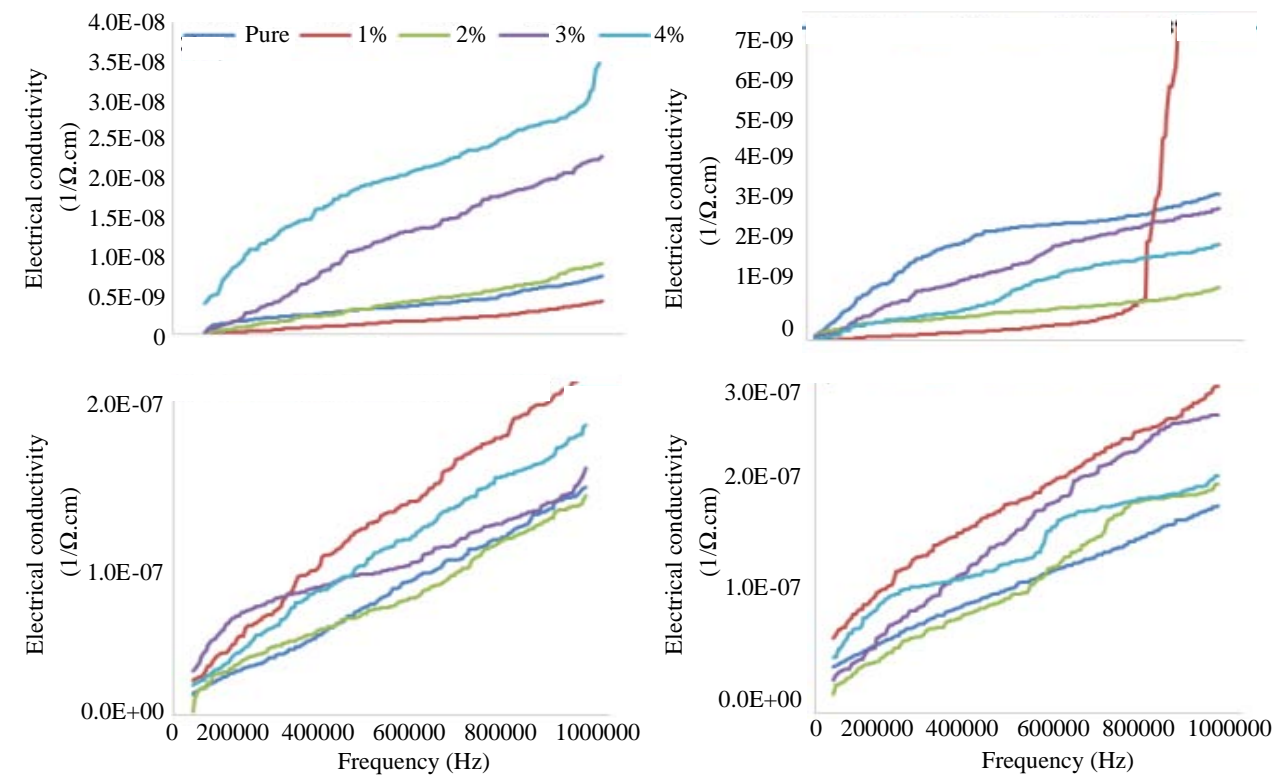

Fig. 10: Electrical conductivity vs. frequency of polymeric mixture nanocomposite with various quantities of ( $\mathrm{ZnO}$ ) nanoparticles

Electrical conductivity is one of the useful methods to understand conductivity mechanism. Electrical conductivity of polymeric blend nanocomposites samples with different weight ratios of zinc oxide nanoparticles $(0-4 \%)$ was determined from Eq. 3, Fig. 10 appeared increases of electrical conductivity with frequency increasing and in general with the weight fraction of $(\mathrm{ZnO})$ increasing which could be imputed to increases of segmental mobility of polymer chains near of $(\mathrm{ZnO})$ nanoparticles (El-Nahass et al., 2013). Also, we observed when the temperature is raised, electrical conductivity increases with temperature.

Figure 11 and 12 show the difference of $\left(\varepsilon^{\prime}\right)$ and $\left(\varepsilon^{\prime \prime}\right)$ with the frequency of the prepared films which contain polymeric compositions with various quantities of $(\mathrm{ZnO})$ nanoparticles, at various temperatures. As in two cases, permittivity reached higher values when the frequencies were decreased. This can be maintained when the frequency area the alternation of the field is slow, giving more time for the induced and permanent dipoles to align themselves with the applied field, thus, increasing polarization. Enhanced amounts of $\left(\boldsymbol{\varepsilon}^{\prime}\right)$ especially at reduce frequencies can be diverted to interfacial polarization and/or electrode polarization. Electrode polarization is connected to the build-up of space charges at the electrode's specimen interfaces and is characterizing by highly amounts of $\left(\varepsilon^{\prime}\right)$ and $\left(\varepsilon^{\prime \prime}\right)$, respectively (Gatos et al., 2007; Psarras et al., 2007; Kalini et al., 2010). In polymers increases of dielectric constant with temperature increasing due to the 

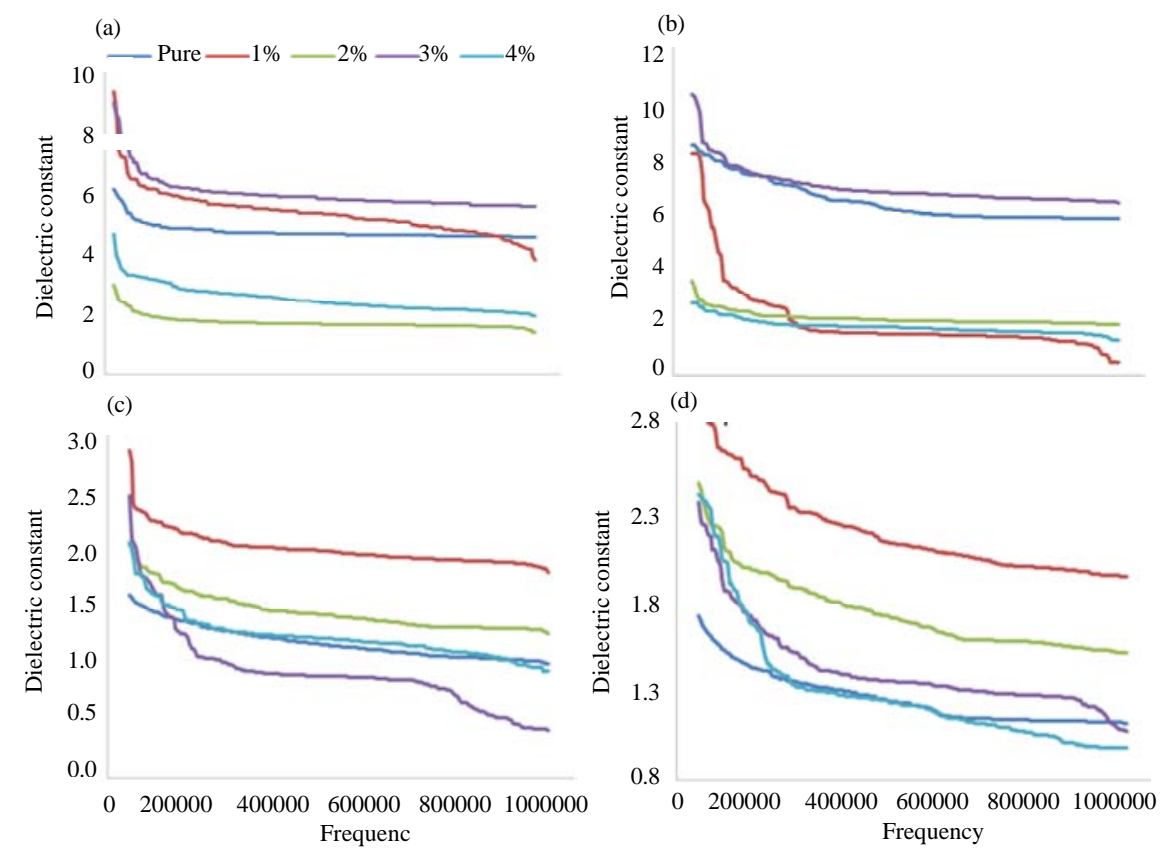

Fig. 11: Real permittivity ( $\varepsilon^{\prime}$ against $\log$ frequency forpolymeric mixture nanocomposite with various quantities of $(\mathrm{ZnO})$ nanoparticles
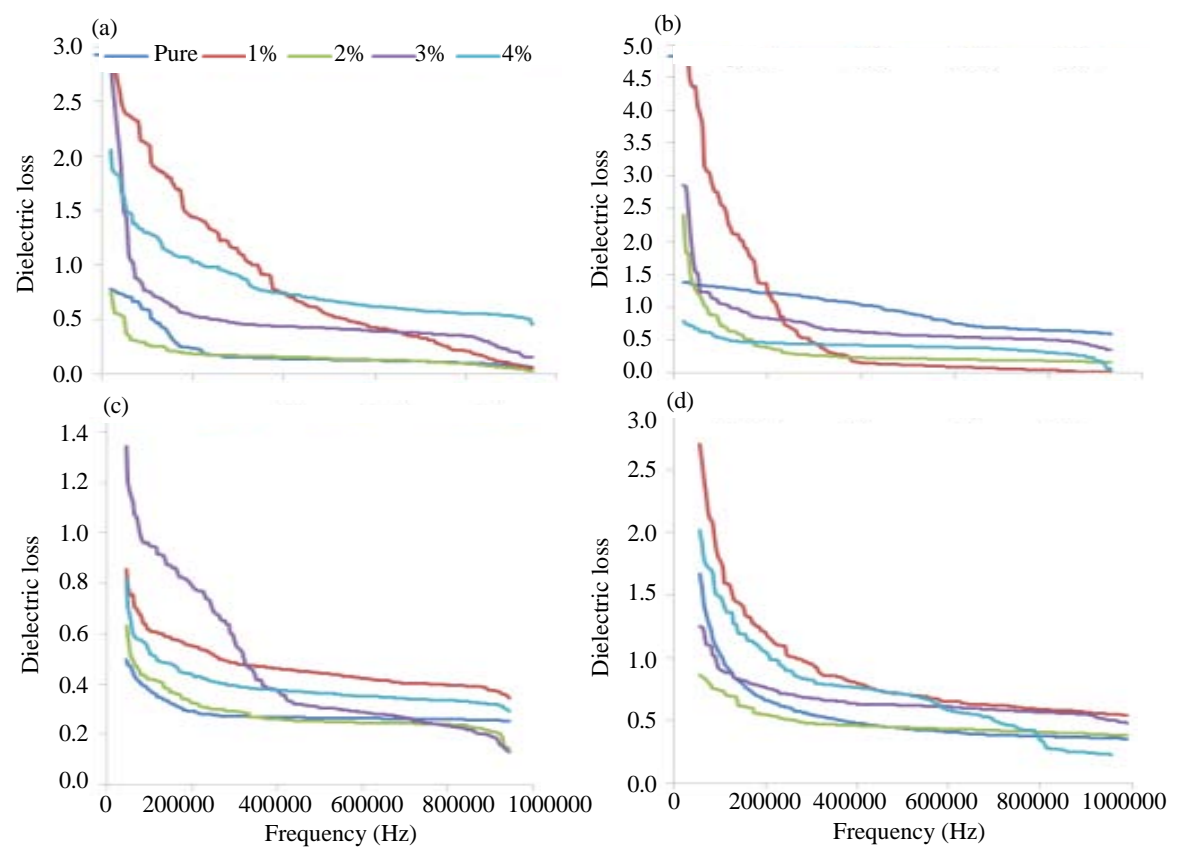

Fig. 12: Imaginary permittivity against log frequency for polymeric mixture nanocomposite with various quantities of $\mathrm{ZnO}$ ) nanoparticles

simplification in orientation of dipoles in polymeric chains that is lead to the degree of dissociation and re-dissociation of ion aggregates increases which causes increase in number of charge carrier density and hence, increasing in (DC) conductivity. 


\section{CONCLUSION}

Nanocomposites films consists of PVA, PVP and PEG blend doped with $0-4 \%$ of $\mathrm{Zinc} O$ xide nanoparticles $(\mathrm{ZnO})$, they named $0-4$, respectively. The dielectric behaviour of the films was investigated. The results appeared that the dopant composition has large influence on the dielectric properties they also appeared that the electrical conductivity amounts for the prepared chips increase with increasing of frequency. Polymeric blend nanocomposites based on PVA-PVP-PEG films with different fractions of zinc oxide nanoparticles was prepared successfully and used. The influence of fractions $(0-4)$ of the zinc oxide on the values of optical factors was investigated. All samples exhibited high absorption and energy band gap type is allowed direct optical in the visible region these samples suitable for potential application and anti-reflection coatingin fabrication solar cells.

\section{REFERENCES}

Al-Saadi, T.M., E.E. Al-Abodi, A.J. Zaier, A. Farouk and A.F. Sulaiman, 2006. Preparation, characterization and thermal analysis of polymeric blend nanocomposites based on PVA-PVP-pegdoped with Zinc oxide nanoparticles. ARPN. J. Eng. Appl. Sci., 13: 3246-3250.

Buba, A.D.A. and J.S.A. Adelabu, 2010. Optical and electrical properties of chemically deposited $\mathrm{ZnO}$ thin films. Pacific J. Sci. Technol., 11: 429-434.

El-Nahass, M.M., H. Kamal, M.H. Elshorbagy and K. Abdel-Hady, 2013. Electrical and dielectric properties of chromotrope $2 \mathrm{R}$ in pellet and thin film forms. Org. Electron., 14: 2847-2853.

Erdem, B., E.D. Sudol, V.L. Dimonie and M.S. El-Aasser, 2000. Encapsulation of inorganic particles via miniemulsion polymerization I. Dispersion of titanium dioxide particles in organic media using OLOA 370 as stabilizer. J. Polym. Sci. Part A. Polym. Chem., 38: 4419-4430.

Ezenwa, I.A., 2012. Synthesis and optical characterization of zinc oxide thin film. Res. J. Chem. Sci., 2: 26-30.

Gatos, K.G., J.M. Alcazar, G.C. Psarras, R. Thomann and J. Karger-Kocsis, 2007. Polyurethane latex/water dispersible boehmite alumina nanocomposites: Thermal, mechanical and dielectrical properties. Compos. Sci. Technol., 67: 157-167.

Greene, L.E., M. Law, D.H. Tan, M. Montano and J. Goldberger et al., 2005. General route to vertical $\mathrm{ZnO}$ nanowire arrays using textured $\mathrm{ZnO}$ seeds. Nano Lett., 5: 1231-1236.
Hau, S.K., H.L. Yip, N.S. Baek, J. Zou and K. O'Malley et al., 2008. Air-stable inverted flexible polymer solar cells using zinc oxide nanoparticles as an electron selective layer. Appl. Phys. Lett., 92: 225-228.

Kalini, A., K.G. Gatos, P.K. Karahaliou, S.N. Georga and C.A. Krontiras et al., 2010. Probing the dielectric response of polyurethane/alumina nanocomposites. J. Polym. Sci. Part B. Polym. Phys., 48: 2346-2354.

Kasap, S.O., 2002. Principles of Electronic Materials and Devices. 2nd Edn., McGraw Hill, New York, USA., ISBN:9780072393422, Pages: 745.

Kawaguchi, H., 2000. Functional polymer microspheres. Prog. Polym. Sci., 25: 1171-1210.

Khan, A.A. and M.M. Alam, 2003. Synthesis, characterization and analytical applications of a new and novel organic-inorganic composite material as a cation exchanger and $\mathrm{Cd}$ (II) ion-selective membrane electrode: Polyaniline Sn (IV) tungstoarsenate. React. Funct. Polym., 55: 277-290.

Khudayer, I.H., B.H.H. Ali, M.H. Mustafa and A.J. Ibrahim, 2018. Investigation of the structural, optical and electrical properties of agInSe 2 thin films. J. Pure Appl. Sci., 31: 37-49.

Lee, J., D. Bhattacharyya, A.J. Easteal and J.B. Metson, 2008. Properties of nano-ZnO/poly (Vinyl alcohol)/poly (Ethylene oxide) composite thin films. Current Appl. Phys., 8: 42-47.

Liang, S., K. Xiao, Y. Mo and X. Huang, 2012. A novel $\mathrm{ZnO}$ nanoparticle blended polyvinylidene fluoride membrane for anti-irreversible fouling. J. Membr. Sci., 394: 184-192.

Madakbas, S., K. Esmer, E. Kayahan and M. Yumak, 2010. Synthesis and dielectric properties of poly (Aniline)/Na-bentonite nanocomposite. Sci. Eng. Compos. Mater., 17: 145-154.

Momen, G. and M. Farzaneh, 2011. Survey of micro/nano filler use to improve silicone rubber for outdoor insulators. Rev. Adv. Mater. Sci., 27: 1-13.

Nejati, K., Z. Rezvani and R. Pakizevand, 2011. Synthesis of $\mathrm{ZnO}$ nanoparticles and investigation of the ionic template effect on their size and shape. Intl. Nano Lett., 1: 75-81.

Psarras, G.C., K.G. Gatos, P.K. Karahaliou, S.N. Georga and C.A. Krontiras et al., 2007. Relaxation phenomena in rubber/layered silicate nanocomposites. Exp. Polym. Lett., 1: 837-845.

Rand, D.A.J., 1979. Battery systems for electric vehicles-a state-of-the-art review. J. Power Sources, 4: 101-143.

Ray, J.R., C.J. Panchal, M.S. Desai and U.B. Trivedi, 2011. Simulation of CIGS thin film solar cells using AMPS-1D. J. Nano Electron. Phys., 3: 747-754. 
Sekine, N., C.H. Chou, W.L. Kwan and Y. Yang, 2009. ZnO nano-ridge structure and its application in inverted polymer solar cell. Org. Electron., 10: 1473-1477.

Sze, S.M., 1981. Physics of Semiconductor Devices. 2nd Edn., John Wiley and Sons Inc., New York, ISBN: 9780471098379, Pages: 868.

Tang, E., G. Cheng, X. Pang, X. Ma and F. Xing, 2006. Synthesis of nano-ZnO/poly(methyl methacrylate) composite microsphere through emulsion polymerization and its UV-shielding property. Colloid Polym. Sci., 284: 422-428.
Walsh, D.J. and S. Rostami, 1985. The Miscibility of High Polymers: The Role of Specific Interactions. In: Key Polymers Properties and Performance, Aseeva, R.M., M. Biswas, S. Packirisamy, S. Rostami and J.D. Walsh et al. (Eds.). Springer, Berlin, Germany, ISBN 978-3-540-15481-5, pp: 119-169.

Xing, F., G. Cheng, B. Yang and L. Ma, 2004. Microencapsulation of capsaicin by the complex coacervation of gelatin, acacia and tannins. J. Appl. Polym. Sci., 91: 2669-2675. 